\section{Schweizer Ärztemissionen}

Die Schweizer Ärztemissionen im zweiten Weltkrieg sind ein spannender Teil der jüngeren Schweizer Geschichte, die mich persönlich nicht zuletzt deshalb interessieren, weil mein ehemaliger Chef, Robert Nicole, an der Rotkreuzmission nach Finnland teilgenommen und darüber berichtet hat. Der Historiker und Arzt Reinhold Busch hat zu dieser Thematik im vergangenen Jahrzehnt mehrere Bücher mit reichhaltigem Quellenmaterial herausgegeben, deren Lektüre für viele historisch interessierte Kolleginnen und Kollegen interessant sein dürfte, weshalb an dieser Stelle nach dem Motto «besser spät als nie» darauf hingewiesen sei. Der an der Universität Heidelberg lehrende Schweizer Historiker Prof. Thomas Maissen hat in der NZZ vom 8. November 2003 (S. 87) eine hervorragende Rezension dieser Reihe verfasst, die wir im Folgenden mit freundlicher Genehmigung von Autor und Verlag im Wortlaut abdrucken.

René Baumgartner, Zumikon

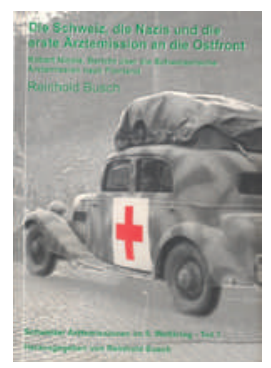

Reinhold Busch

Die Schweiz, die Nazis und die erste

Ärztemission an die Ostfront

Schweizer Ärztemissionen im II. Weltkrieg - Teil 1 Robert Nicole, Bericht über die Schweizerische Ärztemission nach Finnland

Berlin: Verlag Frank Wünsche; 2002.

316 Seiten. $22 €$.

ISBN 978-3-933345-13-4

Ernst Gerber

Im Dienst des Roten Kreuzes

Schweizer Ärztemissionen im II. Weltkrieg - Teil 2 ISBN 978-3-933345-11-0

Elsi Eichenberger

Als Rotkreuzschwester in Lazaretten der Ostfront

Schweizer Ärztemissionen im II. Weltkrieg - Teil 3

ISBN 978-3-933345-14-1
Ernst Baumann Hubert de Reynier Leiden und Sterben in Kriegslazaretten

Schweizer Ärztemissionen im II. Weltkrieg - Teil 5 ISBN 978-3-933345-15-8

Die Ärztemission von 1941/42, die eine Gruppe von schweizerischen Ärzten und Krankenschwestern an die Ostfront brachte, zählt zu den heiklen Punkten der Neutralitätsgeschichte, da die humanitäre Aktion durchaus im Sinn der deutschfreundlichen Initianten um Eugen Bircher einseitig einer Kriegspartei zugute kam einer Kriegspartei, die eine Vernichtungspolitik betrieb. Dies erlebten oder erfuhren die Schweizer, und einer der Ärzte, Rudolf Bucher, berichtete nach seiner Rückkehr in öffentlichen Vorträgen als einer der Ersten über die Vergasungen in Auschwitz. Dieser Verstoss gegen die militärische Schweigepflicht führte zu Verhören, sogar durch Bundesrat Kobelt; Buchers Bericht wurde erst 1967 gedruckt. Darauf reagierte Ernst Gerber zwei Jahre später mit der Veröffentlichung seines überarbeiteten Tagebuchs «Im Dienst des Roten Kreuzes». Er hatte als Pfleger an der ersten und der dritten Mission teilgenommen und wehrte sich mit seiner Darstellung gegen Buchers Vorwurf, die Mehrheit der Mission sei nazifreundlich gewesen. Unvermeidlich empfand sich Gerber jedenfalls unter «Kameraden», als die in kleine Gruppen eingeteilten Schweizer in der russischen Eiseskälte von minus 40 Grad Schwerverletzten wie am Fliessband die erfrorenen Glieder amputierten. $\mathrm{Zu}$ dieser nüchtern aufgezeichneten Normalität des Grässlichen konnten aber auch gelegentliche Sektflaschen und menschliche Kontakte zu sowjetischen Kriegsgefangenen gehören.

Das reich illustrierte Tagebuch wurde von Gerbers Freund Reinhold Busch neu herausgegeben, der in einem weiteren quellenreichen Band nicht nur die Mission an die Ostfront, sondern auch ihre kaum bekannte Vorgängerin von 1940, am Ende des finnischen Winterkriegs, beschreibt. Einer der damaligen Teilnehmer, Guido Piderman, regte 1942 in Absprache mit finnischen Freunden eine weitere humanitäre Aktion der Schweiz an, um sowjetische Kriegsgefangene in Finnland vor dem Hungertod zu retten. Das IKRK und der Bundesrat wollten mit einer solchen «linksgerichteten» Initiative jedoch nichts zu tun haben. Zur gleichen Zeit unterstützten sie aber die zuerst vom deutschen Medizinprofessor Ferdinand Sauerbruch angeregte Mission an der Ostfront, wodurch schweizerische Dienstpflichtige ohne ihr Wissen dem deutschen Kriegsrecht und der Befehlsgewalt der Wehrmacht unterstellt wurden - die ihnen die Behandlung von Russen untersagte. Busch betont den humanitären Charakter des Unterfangens, doch die verdienstvollerweise zusammengetragenen Originalberichte erlauben in ihrer Widersprüchlichkeit auch weniger wohlwollende Bewertungen.

Thomas Maissen, Paris 